\title{
Tracheostomy: Five-Year Review in a West African Hospital
}

\section{Diallo $\mathrm{AO}^{1 *}$, Diallo $\mathrm{OR}^{2}$, Sinayoko $\mathrm{A}^{1}$, Dabo ${ }^{1}$, Bah $\mathrm{B}^{3}$, Diallo $\mathrm{AA}^{1}$ and Traoré $\mathbf{M}^{1}$}

${ }^{1}$ Service ORL \& CCF, Hôpital National Ignace Deen, Guinee

${ }^{2}$ Service d'Odontostomatologie et Chirurgie Maxillo-Faciale, Donka Hospital, Guinee

${ }^{3}$ Service de Neurochirurgie, Donka Hospital, Guinee

*Corresponding author: Diallo Alpha Oumar, Service d'ORL \& Chirurgie Cervico-faciale, Hôpital National Ignace Deen, BP: 2267 Conakry, République de Guinee, Tel: +224628 5294 46; Email: dalphao@hotmail.com

\section{Abstract}

Introduction: The aim of this study was to determine the frequency of tracheotomies in our department over the last five (5) years, list the indications and explain the technique and postoperative follow-up.

Material and Methods: This is a 5-year (January 2013-December 2017) retrospective and analytical study of the records of patients who have had tracheotomies in the ENT and Neck and Facial Surgery department of the Ignace Deen National Hospital in Conakry.

Results: During this period, 48 tracheotomies were performed in the department, with a frequency of $5.42 \%$. The mean age of our patients was 35 years with extremes of 9 years and 67 years. The age group from 10 to 19 was the most affected. The sex ratio was 1.67. All socio-professional categories were affected. The aetiologies of the air obstacle were dominated by cancerous lesions: laryngeal cancer, laryngeal papillomatosis and hypopharyngeal cancer, representing $22.92 \%, 20.83 \%$ and $14.58 \%$ of cases respectively. The tracheotomy was most often carried out under local anaesthesia with a supra isthmic tracheal opening in an inverted $\mathrm{H}$ or I shape in $77.08 \%$ of cases. Complications observed in our series were cervical emphysema and obstructive mucus plug in $6.25 \%$ of cases and 1 case of death, i.e. $2.08 \%$. Early decanulation was performed in $41.67 \%$ of cases.

Conclusion: Tracheostomy is a lifesaving procedure and commonly performed in our practice. A proper technique with carefully selected indications enables minimises the risk of complications.

Keywords: Tracheotomy; ENT; Conakry

Abbreviations: IMV: Invasive Mechanical Ventilation; ARF: Acute Respiratory Failure.

\section{Introduction}

Performed in an emergency or as part of a scheduled surgery, tracheotomy is the surgical opening, either temporary or permanent, of the anterior cervical trachea with the insertion of a cannula through the skin to the lower respiratory tract. It is a life-saving surgical procedure; known since ancient times, commonly used by the
Otorhinolaryngology to bypass a pharyngo-laryngo-tracheal obstacle, and allow difficult intubation or resuscitation. Its frequency varies from one country to another. The range of indications for tracheotomy, which depends on the context of practice, has generally evolved with the development of head and neck surgery and resuscitation [1].

The aim of this study was to determine the frequency of tracheotomy in our department over the last 5 years, list the indications, and describe the technique and the postoperative follow-up. 


\section{Otolaryngology Open Access Journal}

\section{Patients and Methods}

This was a retrospective and analytical study covering a period of 5 years (January 2013-December 2017) carried out in the Otorhinolaryngology and Neck and Facial Surgery department of the Ignace Deen National Hospital (Conakry University Hospital Centre). It involved the clinical records of patients who had undergone tracheotomy during the study period. These records, which included clinical course, operative report and post-operative follow-up. We took into account epidemiological data (age, sex and profession), clinical data (nature of the obstacle and/or indications), therapeutic data (types of anaesthesia, skin incision, tracheotomy site, type of tracheal opening, tracheotomy cannula) and evolutionary data (time taken to wear the cannula, complications).

\section{Results}

Of the 885 surgical procedures performed during the study period, 48 were tracheotomies, i.e. a frequency of $5.42 \%$. We thus performed 09 to 10 tracheotomies per year (Figure 1).

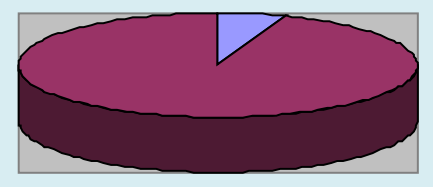

\section{$\square$ Tracheotomy}

$\square$ other interventions

Figure 1: Frequency of tracheotomy at the Ignace Deen National Hospital.

The average age of our patients was 35 , with extremes of
09 and 67 . The age range from 10 to 19 was the most affected (Table 1).

\begin{tabular}{|c|c|c|}
\hline Age brackets (years) & Workforce & Percentage \\
\hline $0-9$ & 2 & 4.17 \\
\hline Oct-19 & 15 & 31.25 \\
\hline $20-29$ & 8 & 16.67 \\
\hline $30-39$ & 6 & 12.5 \\
\hline $40-49$ & 10 & 20.83 \\
\hline $50-59$ & 4 & 8.33 \\
\hline 60 years and over & 3 & 6.25 \\
\hline Total & $\mathbf{4 8}$ & $\mathbf{1 0 0}$ \\
\hline
\end{tabular}

Table 1: Distribution of patients by age group.

There were 30 men and 18 women, with a sex ratio of 1.67. All socio-professional categories were concerned, with a predominance of students (Table 2).

\begin{tabular}{|c|c|c|}
\hline $\begin{array}{c}\text { Socio-professional } \\
\text { Category }\end{array}$ & Workforce & Percentage \\
\hline Students & 18 & 37.5 \\
\hline Officials & 11 & 22.92 \\
\hline No profession & 9 & 18.75 \\
\hline Housewife & 6 & 12.5 \\
\hline Farmer & 4 & 08.33 \\
\hline Total & $\mathbf{4 8}$ & $\mathbf{1 0 0}$ \\
\hline
\end{tabular}

Table 2: Distribution of patients by socio-professional category.

The different aetiologies of the air barrier are shown in Table 3.

\begin{tabular}{|c|c|c|c|}
\hline Indication of tracheotomy & Etiology of the obstacle & Workforce & Percentage \\
\hline \multirow{4}{*}{ Rescue tracheotomies (34) } & Laryngeal cancer & 11 & 22.92 \\
\cline { 2 - 4 } & Papillomatosis laryngitis & 10 & 20.83 \\
\cline { 2 - 4 } & Cancer of the hypo pharynx & 7 & 14.58 \\
\cline { 2 - 4 } & Cancer of the palatine tonsil & 5 & 10.42 \\
\cline { 2 - 4 } & Undetermined (laryngeal oedema) & 1 & 2.08 \\
\hline \multirow{3}{*}{ Safety tracheotomy (11) } & Thyroidectomy for compressive goitres & 5 & 10.42 \\
\cline { 2 - 4 } & Accidental cervical trauma & 4 & 8.33 \\
\cline { 2 - 4 } & Attempt at autolysis & 2 & 4.17 \\
\hline Intubation tracheotomy (3) & Tumour of the oropharynx & 3 & 6.25 \\
\hline
\end{tabular}

Table 3: Distribution of patients according to tracheotomy indication. 


\section{Otolaryngology Open Access Journal}

Faced with late hospital referral, resulting in severe respiratory distress, the ENT had no other option than to open the trachea as a lifesaving option. This rescue tracheotomy represented $70.83 \%$ of the cases in our series and the conditions responsible for these airway obstructions had been, in young adults, laryngeal and hypolarygeal cancer, i.e. $35.42 \%$ of cases. In children, laryngeal papillomatosis was the most common, accounting for $20.83 \%$ of cases.

As for safety tracheotomy and intubation tracheotomy, goiters with tracheomalacia $(10.42 \%)$ and accidental or homicidal neck trauma $(12.50 \%)$ were the reported causes. The tracheotomy was performed under local anaesthesia in 43 patients, i.e. $89.58 \%$. For the five others $(10.42 \%)$ the operation was performed under general anaesthesia.

The skin incision was horizontal in all patients. Compared to the thyroid isthmus, the site of the tracheotomy was supra isthmic in 37 cases $(77.08 \%)$, transisthmic in 5 cases $(10.42 \%)$ and sub isthmic in six cases $(12.50 \%)$. After opening the trachea in an "I" or inverted " $\mathrm{H}$ " position, all patients had been fitted with a low-pressure balloon cannula. The post-operative follow-up was simple in 42 cases ( $87.5 \%$ ). However, we recorded three cases of cervical emphysema (6.25\%), 3 cases of mucus plugging $(6.25 \%)$, one of which was fatal $(2.08 \%)$.

Decanulation times were variable. Twenty (20) patients, i.e. $41.67 \%$, had been decannulated before 7 days. Decanulation difficulties were encountered in laryngeal papillomatosis $(\mathrm{n}=10)$ with delays varying between 8 days and 1 year. Cannulation was definitive for 18 patients with a cancerous pathology (Table 4).

\begin{tabular}{|c|c|c|}
\hline Decanulation times & Workforce & Percentage \\
\hline Before 7 days & 20 & 41,67 \\
\hline 8 to 30 days & 6 & 12,50 \\
\hline 31 days to 12 months & 4 & 08,33 \\
\hline Decanulation impossible & 18 & 37,50 \\
\hline Total & 48 & 100 \\
\hline
\end{tabular}

Table 4: Distribution according to decanulation times.

\section{Discussion}

In the management of acute respiratory failure, tracheotomy remains a life-saving gesture that is still common in our practice. On average 9 to 10 tracheotomies were performed in our department each year. The same datas were reported in other subsaharian African countries with an annual rate of eight in Burkina Faso [2], 8.4 in Congo Brazzaville [3] and 10.42 in Gabon. Indeed, the inadequacy of the technical facilities, in terms of qualified personnel (anaesthetists, surgeons) and resuscitation equipment, often leads us to give priority to surgical tracheotomy in the face of a respiratory emergency, which could endanger the patient's vital prognosis in the short term.

In the western countries where the management of acute respiratory failure (ARF) is more the responsibility of the internsivist and respiratory therapy teams than of the ENT surgeon, surgical tracheotomy has given way to orotracheal intubation or percutaneous tracheotomy [4]. However, the results of the international survey published in 2013 by Estéban, et al. [5], had confirmed the progression of tracheotomy in intubated patients from $11 \%$ in 1998 to $14 \%$ in 2010.

Tracheotomy was performed more frequently in men between the ages of 10 to 19 and 40 to 49 as in most studies in subsaharian Africa [2,3]. Several authors [2,3] had reported male dominance. In our series, students were the most affected socio-professional strata. In contrast, to the study by Sérémé, et al. [2] who reported a predominance of farmers and housewives.

The main indications for tracheotomy in our series were malignant tumours of the upper aero digestive tract. This finding is similar to those described in the literature $[2,3,6]$. In France [1,7], ARI with prolonged ventilation and difficult weaning from invasive mechanical ventilation (IMV) are among the indications generally encountered for performing tracheotomy in adults. In children, the main indication in our series was laryngeal papillomatosis. It was also found in the series of Akolbout, et al. [8] in Congo.

The importance of respiratory distress justifies the use of local anaesthesia for tracheotomy. However, in the case of scheduled operations where the tracheotomy is part of the whole surgical procedure, we use general anaesthesia $[1,2,9]$. The horizontal skin incision had been used in all our patients for cosmetic reasons and can be more easily integrated into a possible cervical surgery for laryngeal or cervical tumours in agreement with several authors [2,3]. The vertical skin incision proposed by some authors Itiere Odzili FA, et al. [3], particularly for emergency tracheotomies, was not performed in our series.

The supra-isthmic tracheal approach was the most common in our series. We recommended it in pharyngolaryngeal cancer pathology, where the high, supra isthmic tracheotomy seems more indicated, because it limits the spread of the disease and facilitates the tracheostomy in case of total laryngectomy or total pharyngo-laryngealectomy.

The sub-isthmic approach is easier to perform (quicker access to the trachea). This ease is a not insignificant 


\section{Otolaryngology Open Access Journal}

argument in emergencies and under local anaesthesia. We recommend it in non-cancerous pathology, but reject it in laryngeal papillomatosis because it would favour tumour migration towards the trachea [10]. The trans-isthmic approach, provides greater safety in the at-risk postoperative period, at the expense of a longer procedure. It had been performed in the safety tracheotomy, in sleeping patients who had already undergone thyroidectomy.

Regarding the tracheal opening, the "I" incision was used in all the patients in our series. This reduces the risk of a complete section of the trachea or stenosis at a later stage. A major constraint of tracheotomy is the availability of the tracheotomy cannula. Under ideal conditions, only complete silver or acrylic cannulas are recommended [3]. This was not always the case in our practice setting. In some cases, we had to insert incomplete cannulas, which resulted in obstructive mucous plugging in three of our patients, one of whom was fatal. These complications remind us that tracheotomy is not an insignificant procedure. This surgical operation must be performed by an experienced surgical team with welltrained paramedical staff.

\section{Conclusion}

Still common in our practice, tracheotomy allows the surgeon to stabilize the patient in order to establish an adequate management. The mastery of the technique and the indications by an experienced surgical team minimises the risks of these complications.

\section{References}

1. Girault C, Gacou A (2017) Place of tracheostomy and humidified high flow oxygen therapy for weaning from mechanical ventilation. Rev Mal Respir 34: 465-476.
2. Sereme $M$, Ouedraogo B, Gyebre $Y$, Zagre N, Ouédraogo $\mathrm{R}$, et al. (2010) Trachéotomie d'urgence au service d'orl du chu Yalgado Ouedraogo de Ouagadougou. Annales de l'Université de Ouagadougou 8: 195-207.

3. Itiere Odzili FA, Otiobanda GF, Ondzotto G (2013) Tracheostomy at Brazzaville University Hospital. Rev Afr Chir Spéc 7(2): 11-14.

4. Cheung NH, Napolitano LM (2014) Tracheotomy: epidemiology, indication, timing, technique, and outcomes. Respir Care 59(6): 895-919.

5. Esteban A, Anzueto A, Alia I (2000) How is mechanical ventilation employed in the intensive care unit? An international utilization review. Am J Respir Crit Care Med 161(5): 1450-1458.

6. Ahn D, Sohn JH, Park JY (2013) Surgical complications and recurrence after central neck dissection in papillary thyroid carcinoma. Asus Nasus larynx 22: 381-385.

7. François B, Noura SD, Delphine M, Youssef B (2015) Tracheotomy and weaning from the ventilatory support Pratic Anesth Réa 14(4): 236-242.

8. Akolbout D, Itiere Odzili FA, Ngouoni CG, Ondzotto G, Otouana B, et al. (2016) Emergency Tracheostomy In 55 Cases: Brazzaville CHU Experience. Ann Univ Marien NGOUABI 16(1): 12-18.

9. Diop EM, Tall A, Diouf R, Ndiaye IC (2000) Management of laryngeal foreign bodies in children in Senegal. Arch Pédiatrie 7(1): 10-15.

10. Ndiaye M, Ndiaye I, Itiere O, Tall A, Diallo BK, et al. (2008) Papillomatose laryngée de l'enfant. J Fr ORL 94: 379-382.

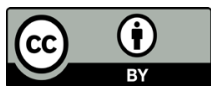

